\title{
Distribution of low-frequency earthquakes accompanying the very low frequency earthquakes along the Ryukyu Trench
}

\author{
Mamoru Nakamura
}

\begin{abstract}
This study investigated the activity and distribution of low-frequency earthquakes (LFEs) accompanying the very low frequency earthquakes (VLFEs) in the central and southern Ryukyu Trench. This investigation was based on shortperiod seismometer waveforms obtained by the Japan Meteorological Agency from April 2004 to December 2015. The LFEs were detected using the Envelope Correlation Method, and the hypocenter locations were established using the arrival time difference of the envelope. The arrival times of the P- and S-phases were selected for events in which conspicuous $\mathrm{P}$ and $\mathrm{S}$ arrivals were observed and their hypocenters were determined. The results showed that LFEs are distributed 30-50 km from the trench axis in the Okinawa and Yaeyama areas. These areas correspond to a slab depth of 12-25 km. The LFEs and VLFEs occurred in association with slow slip events (SSEs) in the Okinawa and Yaeyama areas, indicating that they are induced by SSEs in the Ryukyu Trench. Moreover, the SSEs, LFE-VLFEs, and thrust-type ordinary earthquakes exhibit separate distributions. This suggests change in the frictional condition at the slab depth of 12-25 km along the trench axis in the Ryukyu subduction zone. In the southern Ryukyu Trench, LFEs occur approximately $50 \mathrm{~km}$ from the SSE faults, suggesting that SSEs trigger the LFEs near the southern Ryukyu Trench.
\end{abstract}

Keywords: Low-frequency earthquake, Very low frequency earthquake, Slow slip event, Slow earthquake, Ryukyu Trench, Subduction

\section{Background}

Globally, in the recent decades, various types of slow earthquake have been detected in subduction zones. These events reflect the stress release process at the subducting plate interface over geodetic to seismic time scales (Obara and Kato 2016). As this process releases accumulated stress and redistributes it within the surrounding area, it can promote the occurrence of large interplate earthquakes (Ito et al. 2013; Kato and Nakagawa 2014; Kato et al. 2016). Therefore, clarification of the distribution of slow earthquakes would contribute to the monitoring of the stress accumulation and release processes at the plate interface.

*Correspondence: mnaka@sci.u-ryukyu.ac.jp Faculty of Science, University of the Ryukyus, Nishihara-cho, Okinawa 9030213, Japan
In the Ryukyu Trench, the Philippine Sea Plate is subducting beneath the Eurasian or Okinawa Plate (Bird 2003; Seno et al. 1993). Historically, large ( $\mathrm{Mw}>8)$ earthquakes have not occurred in this region for 300 years (Ando et al. 2009). The seismic coupling, which is the ratio of the seismically released moment to the accumulated moment due to plate subduction, is 5\% over approximately 100 years (Peterson and Seno 1984). This suggests the lack of, or a very narrow, plate-coupling zone in the Ryukyu Trench. However, numerical modeling of devastating tsunamis has revealed that an M8 class interplate earthquake occurred in 1771 in the southern Ryukyu Trench (Nakamura 2009). The occurrence of such an anomalous event suggests that the state of interplate coupling is unknown.

Over the past decade, various types of slow earthquake have been detected in the Ryukyu Trench. Slow slip 
events (SSEs), which are geodetically slow earthquakes with rupture durations of approximately one month, have been detected in the southern Ryukyu Trench. These SSEs occur repeatedly at intervals of six to seven months (Heki and Kataoka 2008) with magnitudes of 6.4-6.7. However, Nishimura (2014) found the occurrence of short-term SSEs with durations of two weeks or less to be distributed heterogeneously along the Ryukyu Trench. The major clusters of these short-term SSEs are located in the east of Amami Island, southeast of Okinawa Island, and beneath Iriomote Island.

Very low frequency earthquakes (VLFEs), which are categorized as seismically slow earthquakes with rupture durations of tens of seconds, occur along the trench axis (Asano et al. 2015; Nakamura and Sunagawa 2015). The centroid moment tensor (CMT) solutions of the VLFEs are predominantly reverse-type faults (Ando et al. 2012), suggesting that the VLFEs occur on the subducted plate interface or splay faults in the accretionary prism. The main clusters of VLFEs are distributed on the trench side near Amami, Okinawa, and Iriomote islands (Fig. 1a).

Low-frequency earthquakes (LFEs), which are categorized as seismically slow earthquakes with dominant frequencies of several Hertz, have been observed by ocean-bottom seismometers in the southern Ryukyu Trench (Arai et al. 2016). For example, a swarm of LFEs was detected at the depth of $15-25 \mathrm{~km}$ in the southern Ryukyu Trench.

The distribution of LFEs can reveal important information regarding the location of stress release by seismically slow earthquakes on the subducting plate interface; however, their detection is difficult in the Ryukyu Trench area. Generally, the magnitudes of LFEs are very small, in the range $0.0-1.5$ for the case of the Nankai Trough (Ide et al. 2007; Shelly et al. 2006). As this small signal could be obscured by high levels of ground noise, such as anthropogenic noise and ocean waves, it is generally difficult to detect their signals using the ground-based seismometers installed on small islands.

The distributions of VLFEs and LFEs show the state of slip on the plate interface on seismic time scales, and their differences relative to that of SSEs reflect the distribution and degree of aseismic motion on the plate interface. However, because the horizontal location error of VLFEs is so large that accurate location determination is difficult, establishing the distribution of seismically slow earthquakes based on VLFEs is imprecise. The dominant frequency of the LFE waveform is several Hertz, and therefore, the estimated error of LFE location would be within several kilometers, where the coverage of stations is appropriate for hypocenter location. Thus, this study determined the hypocenter locations of the LFEs accompanying the VLFEs, and it clarified the spatial relationship between SSE faults and the hypocenters of LFEs.

\section{Observations of LFEs in the Ryukyu Trench}

Although the detection of LFEs is extremely difficult on the Ryukyu Islands, LFE signals have been recorded occasionally in the seismograms of seismometers based on the islands. For example, LFEs in the Ryukyu Trench were detected when the VLFE swarm occurred. Figure 2 shows the 1-h waveforms of LFEs and VLFEs acquired at 12:00-13:00 on June 1, 2005 (UT) at IGK, which is located on Ishigaki Island (Fig. 1b). Several arrivals of VLFEs are recorded in the $0.02-0.05 \mathrm{~Hz}$ band-pass-filtered waveform (Fig. 2b). Corresponding to the arrivals of the VLFEs, the LFEs can be detected in the $2-4 \mathrm{~Hz}$ band-pass-filtered waveform (Fig. 2a). The envelopes of the LFEs are similar to those of the VLFEs (Fig. 2c-e). Figure 3 shows the horizontal envelope waveforms in the Yaeyama area, illustrating the near-simultaneous arrivals of the waves from the LFEs at the various stations. The arrival time is slightly faster at KUROSH, ISHIG2, IRIOM2, and HATERS than at TARAMA and YONAGU, and the arrivals of the LFEs are difficult to detect at TARAMA. This implies that the waves of the LFEs propagated from the vicinity of the south of Iriomote Island.

Figure 4 shows that the spectra of a pair of LFE and VLFE traces are dominant at high $(0.8-6.0 \mathrm{~Hz})$ and low $(0.03-0.20 \mathrm{~Hz})$ frequencies, where the peak of background noise occurs at $0.4 \mathrm{~Hz}$. The amplitude of the VLFE is greater than the background noise level within the frequency range $0.03-0.20 \mathrm{~Hz}$. The amplitude of the LFE is three times that of the background noise level at frequencies of $0.8-6.0 \mathrm{~Hz}$. The amplitude of the ordinary earthquake (M2.4) is also greater than the background noise level at frequencies of $2.0-8.0 \mathrm{~Hz}$. The amplitude of the ordinary earthquake is greater than that of the LFEs within the frequency range of $3.0-8.0 \mathrm{~Hz}$.

Signals of LFEs are frequently observed in the Okinawa and Yaeyama areas, corresponding to the region of clustered VLFEs (Nakamura and Sunagawa 2015) and the faults generating the short-term SSEs (Nishimura 2014). The VLFEs became activated during the time of occurrence of SSEs in the Yaeyama area (Nakamura and Sunagawa 2015), suggesting that the occurrence of SSEs is related to VLFEs.

\section{Methods \\ Waveform data}

The data used were recorded from April 1, 2004, to December 31, 2015. The data were analyzed for the period when the VLFE swarm activity occurred. The LFEs were analyzed using the waveforms of short-period seismometers deployed in the Ryukyu Arc by the Japan 

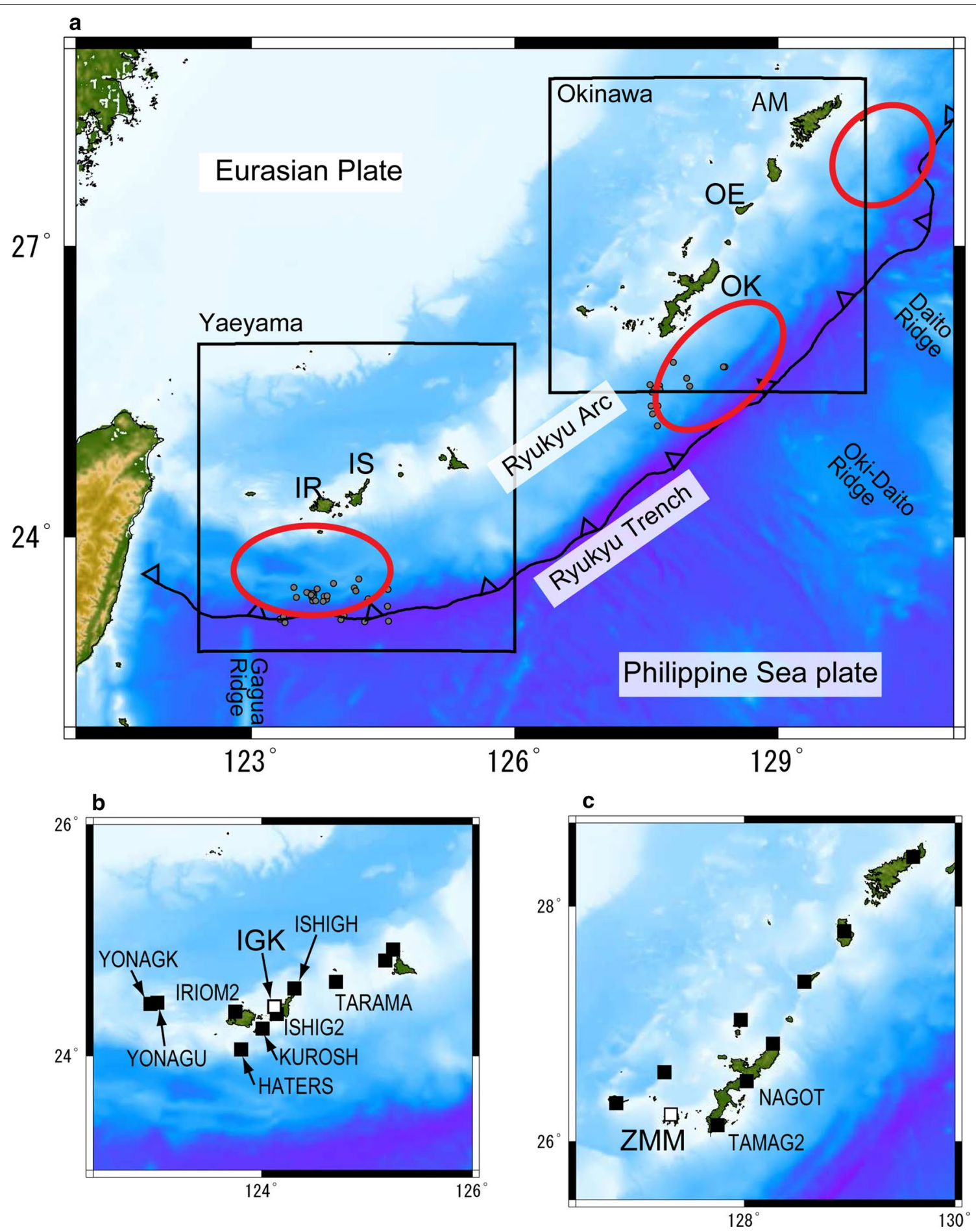

Fig. 1 Distributions of very low frequency earthquakes (VLFEs) and observation stations within the study area. a IR Iriomote Island, OE Okinoerabu Island, OK Okinawa Island, AM Amami Island. Red ovals show the major clusters of VLFEs (Nakamura and Sunagawa 2015). Small gray circles show the hypocenters of the ordinary earthquakes whose amplitudes were compared with those of the LFEs in Fig. 11. b Enlarged area for the Yaeyama region. Open squares show the F-net stations; solid squares show the JMA stations. c Same as $\mathbf{b}$ but for the Okinawa area 

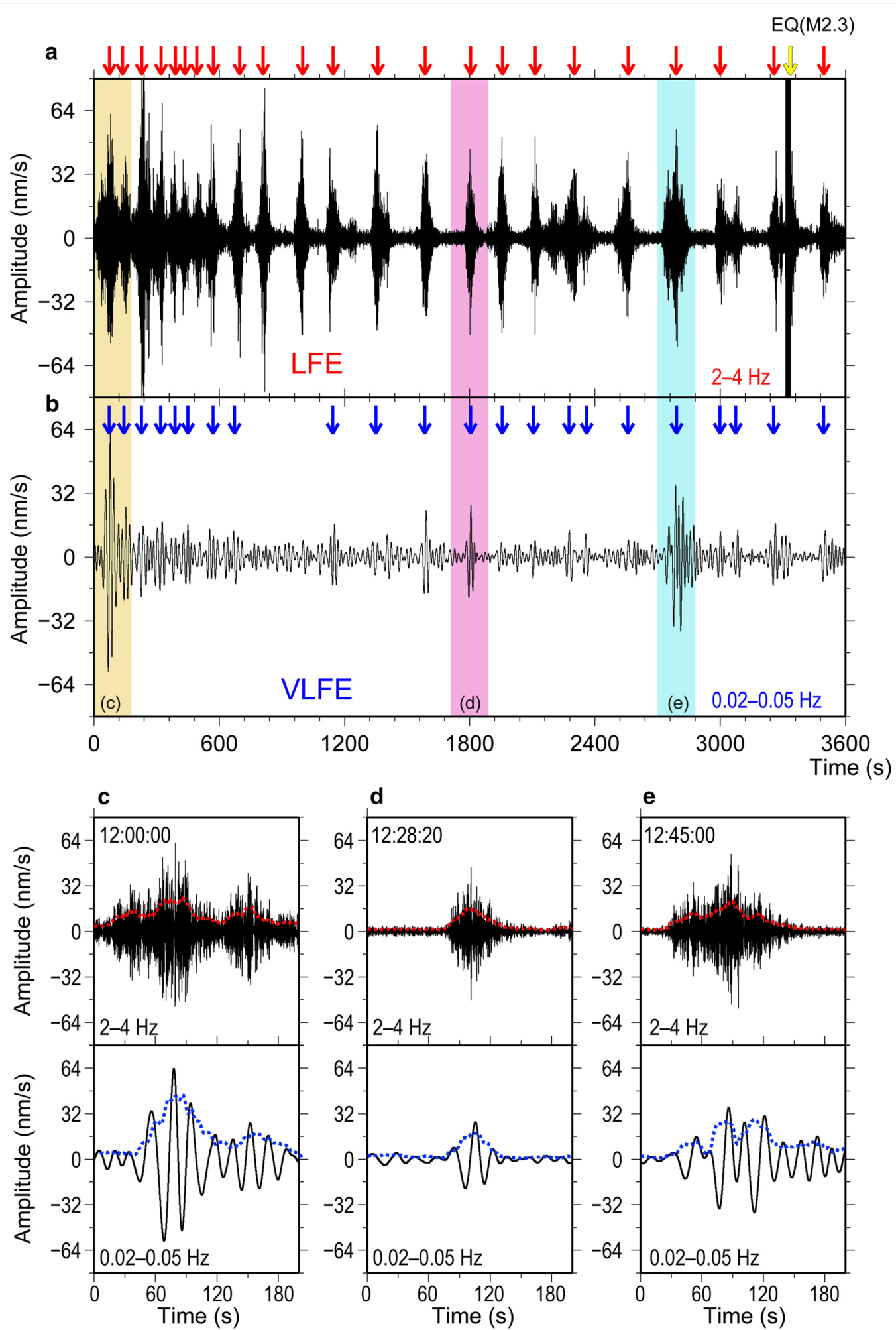

Fig. 2 Example of waveforms at IGK. a 2-4 Hz band-pass-filtered waveform. Data acquired at 12:00-13:00 on June 1, 2005 (UT). Red arrows show the low-frequency earthquakes (LFEs). Yellow arrows show the ordinary earthquakes. b $0.02-0.05 \mathrm{~Hz}$ band-pass-filtered waveform. Time range is the same as $\mathbf{a}$. Blue arrows show the very low frequency earthquakes (VLFEs). c Examples for the event at 12:00:00 enlarged from $\mathbf{a}$ and $\mathbf{b}$. Upper and lower figures show the waveforms of LFEs and VLFEs, respectively. Red and blue dotted lines show the root-mean-square (RMS) waveforms of 2.00-4.00 and 0.02-0.05 Hz band-pass-filtered waveforms using 10-s boxcar window. d Same as c but for the event at 12:28:20. e Same as c but for the event at 12:45:00 


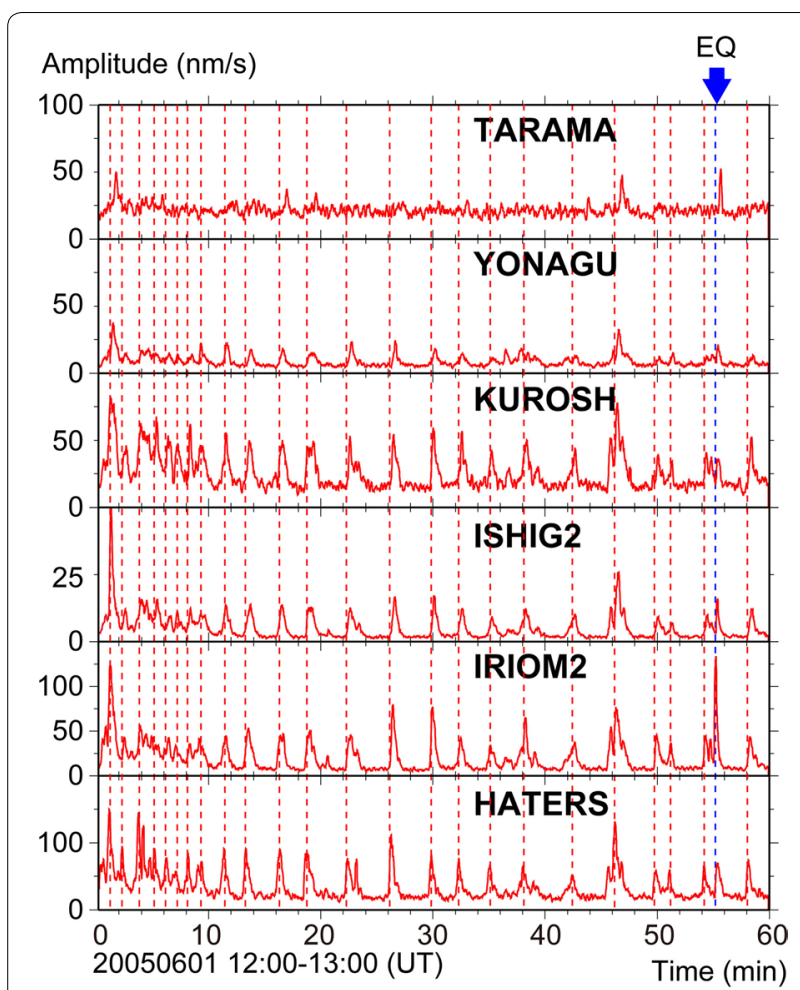

Fig. 3 Envelope waveforms at the stations in the Yaeyama area. Envelopes were computed using the root-mean-square (RMS) amplitude with 10-s boxcar windows and the composite horizontal components of the seismograms, which were band-pass-filtered within the range 1-2 Hz. The red dotted lines show the low-frequency earthquakes (LFEs). Blue dotted line shows the ordinary earthquake

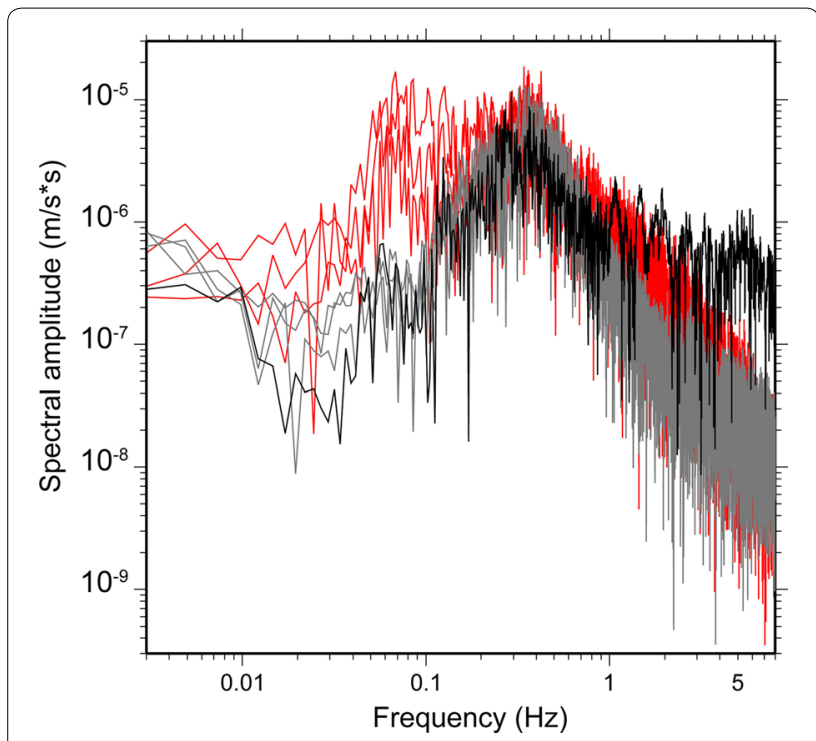

Fig. 4 Spectral amplitudes of various sources. Time window for each calculation was set to $400 \mathrm{~s}$. Red lines show the low-frequency earthquakes (LFEs) and very low frequency earthquakes (VLFEs) that occurred during 12:00-13:00 on June 1, 2005 (UT). Black line shows the ordinary earthquake (magnitude 2.4), which occurred at 10:44 on May 27, 2005 (UT). Gray lines show the ambient noise
Meteorological Agency (JMA), and F-net broadband seismometers deployed by the National Research Institute for Earth Science and Disaster Resilience. The natural period of the short-period seismometers is $1 \mathrm{~s}$. Nine short-period seismometers and one broadband seismometer were used for hypocenter determination in the Okinawa area (Fig. 1c). Among these, station NAGOT was installed on February 1, 2010, and this station was used for hypocenter determination after this date. Ten short-period seismometers of the JMA were used for hypocenter determination in the Yaeyama area (Fig. 1b). Among these, stations ISHIGH and YONAGK were installed on February 1, 2010, and similarly, these stations were used for hypocenter determination after their implementation.

\section{Hypocenter determination using relative arrival time difference of S-waves}

The waveforms were analyzed for examples of LFE events using the Envelope Correlation Method (Obara 2002). This method calculates the cross-correlation of the envelopes of waveforms between two stations, and it was used to detect the arrival time differences between the LFE envelopes of the stations in the network.

The root-mean-square (RMS) amplitudes for 10-s intervals were computed to create envelopes by combining the waveforms of two horizontal components, which were band-pass-filtered in the frequency range of 1-2 Hz. Then, the cross-correlation between the waveforms of two stations was analyzed, and the timing of the peak of the cross-correlation was regarded as the arrival time difference between the two stations. The arrival time difference was adopted when its cross-correlation was $>0.7$. The hypocenters were determined when the crosscorrelation of six or more stations satisfied this criterion. Then, the hypocenter was computed using the method of Chao et al. (2013), which computes the hypocenter location by grid-search method using the pairs of travel time differences of the envelopes in the seismic network. The velocity structure model used in this study was the JMA2001 (Ueno et al. 2002). The S-wave travel time was used because the envelope of the horizontal component is assumed dominant for the S-wave. Ordinary earthquakes were deleted from the determined LFE catalog using the JMA catalog.

\section{Hypocenter determination using relative arrival time differences and S-P time differences}

Almost all LFEs have spindle-shaped waveforms such that conspicuous $\mathrm{P}$ - and $\mathrm{S}$-wave arrivals are generally obscured. However, conspicuous P- and S-phases could be detected in some waveforms of the LFEs (Fig. 5). For such events, the selection of the P- and S-phases was 
performed manually using the polarization of the three components of the waveforms. Then, the hypocenters were determined using the arrival time differences of the envelopes and the S-P time delays by means of the following equation, which was modified from the equation of Chao et al. (2013) (their Equation A1): of the ordinary earthquakes were $94-166 \mathrm{~km}$ from IGK (Fig. 1a).

The average noise levels at high $(2.00-4.00 \mathrm{~Hz})$ and low $(0.02-0.05 \mathrm{~Hz})$ frequencies were computed, and the RMS amplitudes at these frequencies were calculated using the band-pass-filtered vertical waveforms at IGK. The period

$$
\operatorname{rms}_{(x, y, z)}=\sqrt{\left(\frac{\sum_{i=1, j=2}^{n_{\mathrm{s}}} w_{\mathrm{s}}\left(\Delta t_{i, j}^{\text {theo } \_}-\Delta t_{i, j}^{o b s}{ }^{\text {obs }}\right)^{2}+\sum_{i=1, j=2}^{n_{\mathrm{sp}}} w_{\mathrm{sp}}\left(\Delta t_{i, j}^{\text {theo } s p}-\Delta t_{i, j}^{\text {obs_sp }}\right)^{2}}{w_{\mathrm{s}} n_{\mathrm{s}}+w_{\mathrm{sp}} n_{\mathrm{sp}}}\right)},
$$

where theo_s and obs_s denote the theoretical and observed travel time differences of S-waves, respectively; theo_sp and $o b s \_s p$ denote the theoretical and observed travel time differences between $\mathrm{P}$ - and $\mathrm{S}$-waves (S-P times), respectively; and $n_{\mathrm{s}}$ and $n_{\mathrm{sp}}$ represent the number of pairs of travel time differences of $\mathrm{S}$-waves and the number of S-P times, respectively. The theoretical travel time difference $\left(\Delta t_{i, j}\right)$ is computed for each pair of stations, $i$ and $j$, using the difference in S-wave travel times from the hypocenter $(x, y, z)$ to the stations $(i, j)$ considering the one-dimensional velocity structure. The velocity structure model used in this calculation was the JMA2001 (Ueno et al. 2002). $w_{\mathrm{s}}$ and $w_{\text {sp }}$ denote the weighted travel time differences of S-waves and S-P time delays, respectively. The $w_{\mathrm{s}}$ and $w_{\mathrm{sp}}$ values were set to 0.2 and 1.0, respectively, where if the $w_{\mathrm{s}}$ value was changed from 0.2 to 1.0, the epicenter moved approximately $15 \mathrm{~km}$ toward the islands. The minimum position of the rms was searched using the grid-search method by changing the location of this position with a grid interval of $1 \mathrm{~km}$.

The magnitudes of the LFEs were computed using a formula for magnitude as a function of the maximum amplitude and the epicentral distance of the event (Watanabe 1971).

\section{Comparison of maximum amplitude between VLFEs and accompanying LFEs with ordinary earthquakes}

The maximum amplitudes of the pairs of LFEs and VLFEs (LFE-VLFEs) and ordinary earthquakes were compared to investigate their differences. The vertical components of the waveforms of the broadband seismometers at IGK were band-pass-filtered within the frequency ranges of $2.00-4.00$ and $0.02-0.05 \mathrm{~Hz}$ to extract the LFEs and VLFEs, respectively, and the maximum amplitudes of the LFEs and VLFEs were selected. The same procedure was performed for the ordinary earthquakes (M3.2-4.5) that occurred between January 2009 and December 2014. The hypocenters of the ordinary earthquakes were distributed within the area delineated by $23.1^{\circ}-23.7^{\circ} \mathrm{N}, 123.3^{\circ}-$ $124.7^{\circ} \mathrm{E}$ at depths of $<60 \mathrm{~km}$ (Fig. 1a), where the relocated LFE clusters were distributed. The epicentral distances of the calculation was from January 2005 to December 2015, and the calculated RMS values were averaged for the entire period.

The same procedure was performed for the Okinawa area using the waveforms from ZMM (Fig. 1c). The hypocenters of the ordinary earthquakes were distributed within the area delineated by $25.2^{\circ}-25.8^{\circ} \mathrm{N}, 127.5^{\circ}-$ $128.3^{\circ} \mathrm{E}$ at depths of $<60 \mathrm{~km}$ (Fig. 1a), where the cluster of LFEs was located. The epicentral distances of the ordinary earthquakes were 68-123 km from ZMM (Fig. 1a). The average noise levels at ZMM were computed for the frequency ranges of $2.00-4.00$ and $0.02-0.05 \mathrm{~Hz}$ using the same procedure as for IGK.

\section{Results}

\section{Distribution of LFEs}

Figure $6 \mathrm{~b}$ shows that the epicenters of the LFEs in the Okinawa area are concentrated in the south of Okinawa Island (OK-A) and southeast of Okinoerabu Island (OKB). The hypocenters of 943 LFEs can be determined in the Okinawa area. The dimensions of cluster OK-A are 120 and $90 \mathrm{~km}$ perpendicular and parallel to the trench, respectively. Cluster OK-B is elongated perpendicular to the trench axis, and its width parallel to the trench is $\leq 50 \mathrm{~km}$. Although the estimation errors of hypocenters along the trench axis are approximately $10 \mathrm{~km}$, they increase to approximately $100 \mathrm{~km}$ in the direction perpendicular to the trench axis (Fig. 7b, d). The depth of most events was determined to be $0 \mathrm{~km}$; however, the determination error is large because the events were located in an ocean area not covered by seismic stations.

Figure 6a shows that the epicenters of the LFEs in the Yaeyama area are concentrated to the southwest of Iriomote Island (YA-A and YA-B) and the south of Ishigaki Island (YA-C). The hypocenters of 756 LFEs can be determined in the Yaeyama area. Cluster YA-B is densely distributed within an area with diameter of $40 \mathrm{~km}$, and cluster YA-A is more sparsely distributed within an area with diameter of $40-50 \mathrm{~km}$ to the west of cluster YA-B. Cluster YA-C is located to the east of YA-B, and it is concentrated within an area with diameter of $50 \mathrm{~km}$. The error in the estimation of the hypocenters is 


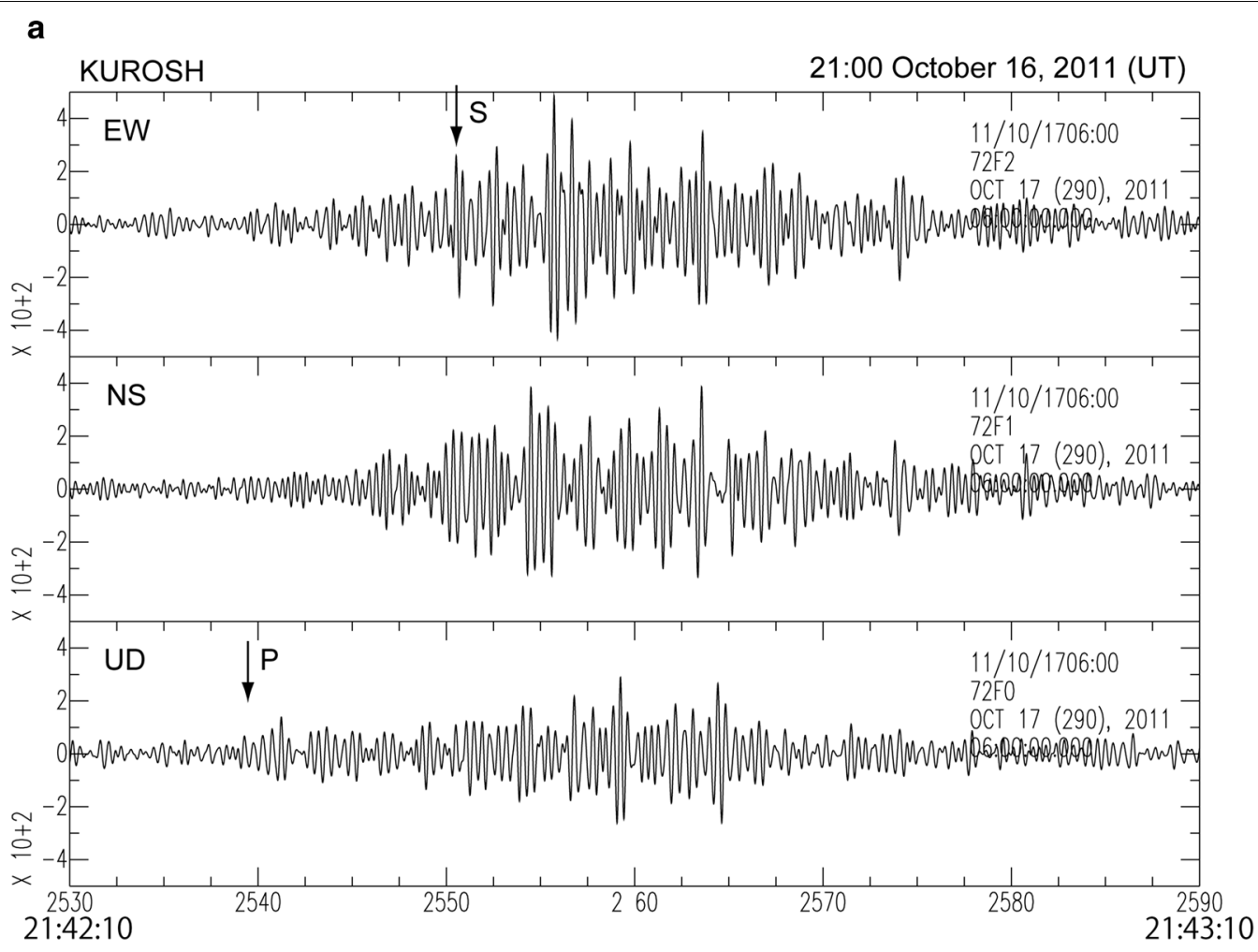

b

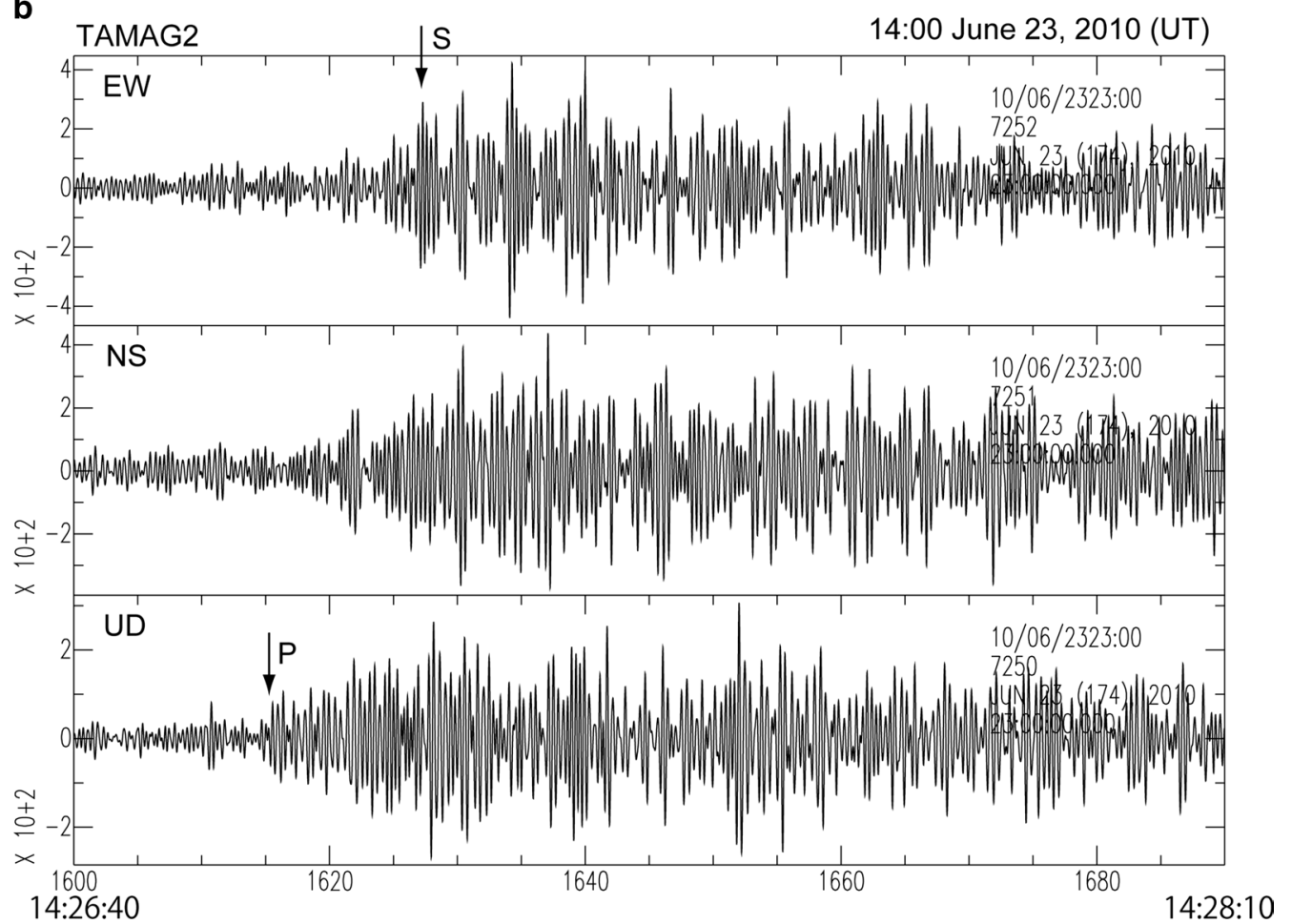

Fig. 5 Three-component seismograms of low-frequency earthquakes (LFEs) from which P and S arrivals were selected. $\mathbf{a}, \mathbf{b}$ The seismograms at KUROSH and TAMAG2, respectively 

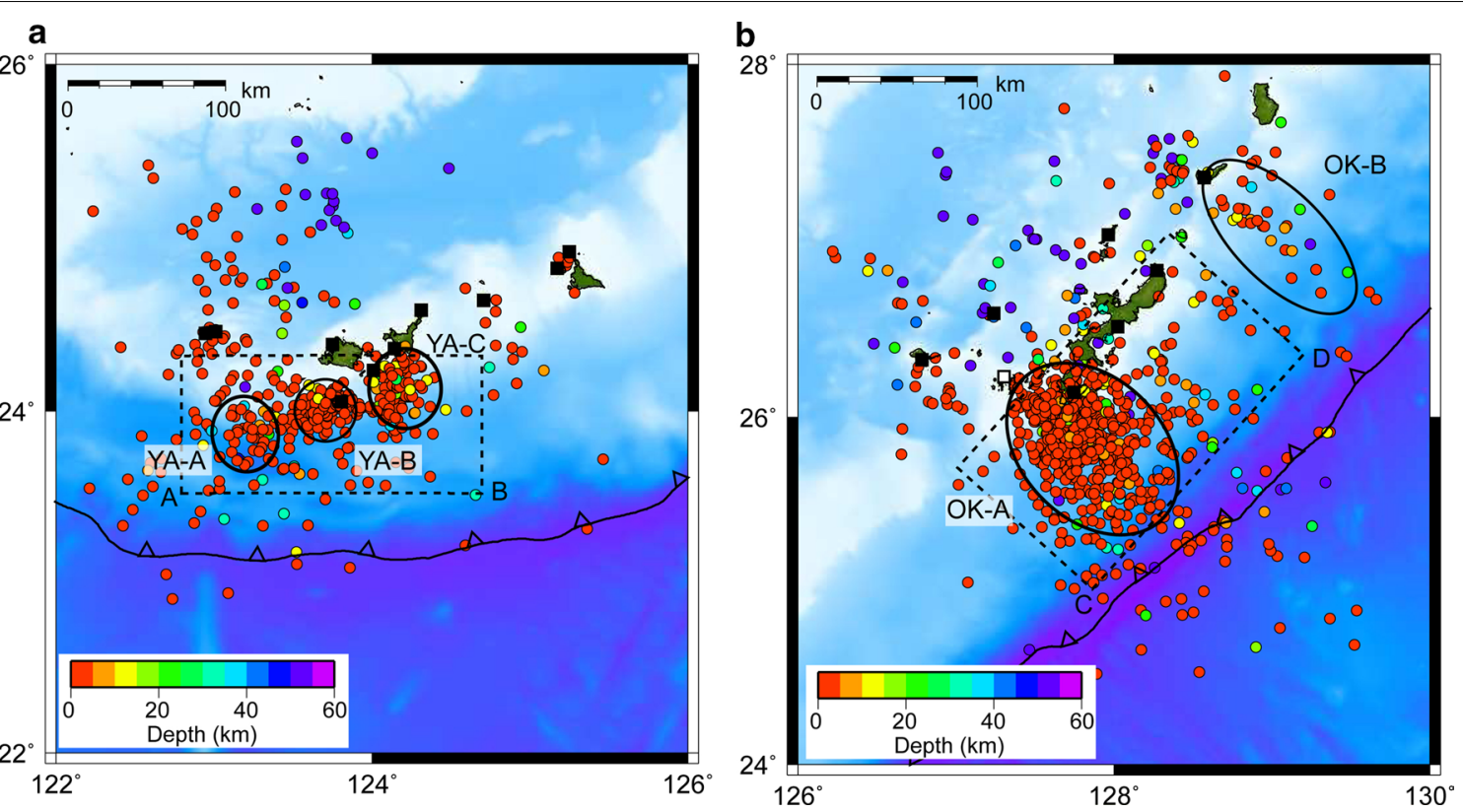

Fig. 6 Distributions of low-frequency earthquakes (LFEs) in the southern and central Ryukyu Trench. a Distribution of LFEs in the Yaeyama area. Circles show the epicenters of LFEs. Solid squares show the JMA stations used in the hypocenter determination. Black circular areas show the clusters of the LFEs. Rectangular area with dotted line denotes the area from which the time-space diagram in Fig. 10 was constructed. $\mathbf{b}$ Distribution of the LFEs in the Okinawa area. Solid and open squares show the JMA and F-net stations, respectively, used in the hypocenter determination. Rectangular area with dotted line denotes the area from which the time-space diagram in Fig. 9 was constructed

approximately $10 \mathrm{~km}$ in the direction along the trench axis; however, the error increases to approximately $100 \mathrm{~km}$ perpendicular to the trench axis (Fig. 7a, c). The depth of most events was determined to be $0 \mathrm{~km}$; however, the determination error is large, and thus, the accuracy of the depth determination is poor.

\section{Time-space distribution of LFEs}

Although a swarm of VLFEs accompanies LFE activity in most cases, LFE activity was sometimes not found during the occurrence of a swarm of VLFEs. The epicenters of the LFEs are concentrated within the area of the VLFE swarm along the trench axis in the Okinawa area (Fig. 8a, b). The VLFEs are distributed at distances of -50 to 100 and 200 to $280 \mathrm{~km}$ along the trench axis (Fig. 8a); however, the distribution of LFEs is slightly narrower ( -80 to 0 and 200 to $250 \mathrm{~km}$ ). The cluster of LFEs is located to the southwest of the VLFEs (Fig. 8a, b), and the LFEs occur mainly to the southwest of the SSE faults. The LFE activity in cluster OK-A remains within the cluster, and migration of the LFE activity along the trench could not be found for most swarms (Fig. 9). Two clusters, which are $70 \mathrm{~km}$ apart, were activated within one week (Fig. 9). If the movement of the activity is the migration of LFEs, then the migration velocity, which is denoted as the ratio of the distance between the clusters to the difference of the timing of the two swarms, is $12 \pm 5.7-51 \pm 14 \mathrm{~km} /$ day.
In the Yaeyama area, the LFEs occur within the VLFE swarm. Similar to the case of the Okinawa area, the SSEs occur when the LFE-VLFE swarms occur. The epicenters of the LFEs are concentrated within the cluster of VLFEs (Fig. 8c, d). Although the VLFEs are distributed at distances of -200 to $50 \mathrm{~km}$ along the trench, the LFEs are distributed at distances of -100 to $30 \mathrm{~km}$ (Fig. 8c, d). The locations of the LFEs, projected parallel to the direction of the Ryukyu Trench, correspond to the locations of the SSEs in the Yaeyama area.

In the Yaeyama area, $51 \%$ of the LFE swarms occur within cluster YA-B; $20 \%$ and $28 \%$ of the LFE swarms occur within YA-A and YA-C, respectively. The activity does not migrate continuously, but it jumps from one cluster to another (Fig. 10). The movement of activity tends to start from YA-B. The activity of $26 \%$ of the LFE swarms shifted from YA-B, while the activity of $13 \%$ of the LFE swarms in YA-A and YA-C shifted to YA-B. The migration velocity is $16 \pm 8.3-72 \pm 34 \mathrm{~km} /$ day (average: $35 \mathrm{~km} /$ day) for the movement from YA-B to YA-A, and it is $9.0 \pm 4.7-$ $15 \pm 6.5 \mathrm{~km} /$ day (average: $12 \mathrm{~km} /$ day) for the movement from YA-B to YA-C, assuming that the spread of the swarm activity can be approximated by the migration velocity.

\section{Comparison of maximum amplitude with noise level}

The maximum amplitudes of the LFEs correlate moderately with those of VLFEs (Fig. 11), i.e., correlation 

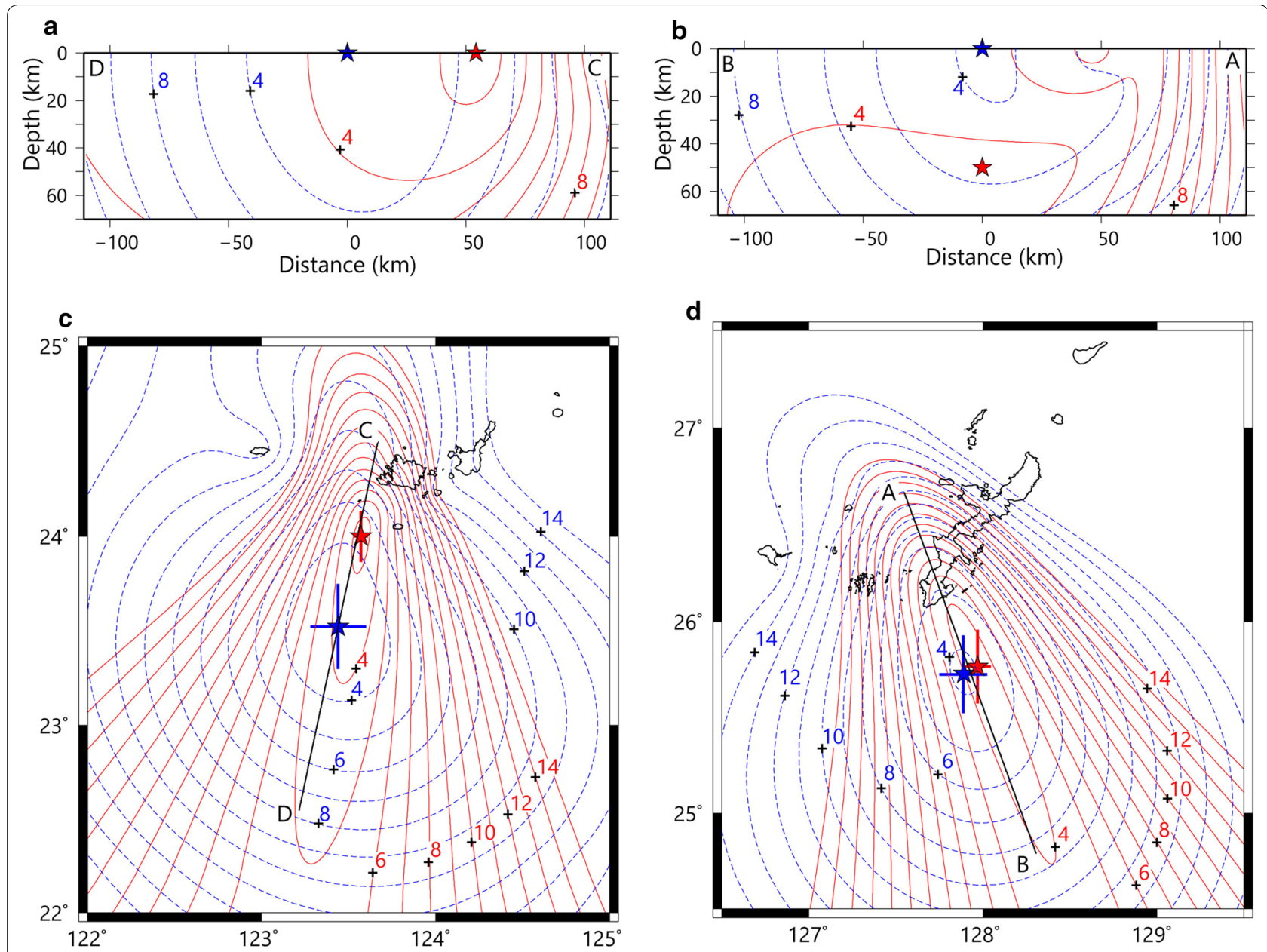

Fig. 7 Hypocenter error distribution of low-frequency earthquakes (LFEs) that occurred in the Okinawa and Yaeyama areas. $\mathbf{a}, \mathbf{b}$ The vertical cross section of hypocenter error distribution. $\mathbf{c}$, d The hypocenter distribution at the depth of $0 \mathrm{~km}$. $\mathbf{b}$ and $\mathbf{d}$ Also show the hypocenter error distribution of the event that occurred at 14:27 on June 23, 2010 (UT). a and c Also show the hypocenter error distribution of the event that occurred at 13:41 on July 23, 2004 (UT). Red contours show the root-mean-square (RMS) differences (in seconds) between the observed and predicted S-phase travel times of the LFEs. Blue contours show the RMS differences (in seconds) between the observed and predicted S-wave travel times and S-P time delays. Stars show the hypocenters obtained by the hypocenter determination

coefficients of 0.49 and 0.48 at IGK and ZMM, respectively. The amplitudes of the LFEs are approximately $1 \%$ than those of ordinary earthquakes, which have similar amplitudes in the low-frequency components. The averaged noise levels within the frequency ranges of $2.00-4.00$ and $0.02-0.05 \mathrm{~Hz}$ at IGK are 3.8 and $2.1 \mathrm{~nm} / \mathrm{s}$, respectively; the averaged noise levels within the same frequency ranges at ZMM are 4.1 and $2.2 \mathrm{~nm} / \mathrm{s}$, respectively.

\section{Distribution of relocated hypocenters by adding S-P time delays}

The relocated LFEs of the Okinawa area occur where the depth of the subducted plate is $12-20 \mathrm{~km}$ (Fig. 12b). The hypocenters of 81 LFEs are determined in the Okinawa area. The magnitude range of the events is -0.6 to 1.9 , and the horizontal hypocenter error is approximately $15 \mathrm{~km}$ (Fig. 7b, d). In the Okinawa area, the relocated epicenters are distributed approximately $40 \mathrm{~km}$ to the southeast of the previous ones (Fig. 13b). Furthermore, the distribution of the LFEs can be divided into three major clusters (OK-RA, OK-RB, and OK-RC) (Fig. 12b). Cluster OK-RA is located at $25.7^{\circ} \mathrm{N}, 127.8^{\circ} \mathrm{E}$. This cluster is distributed approximately $30 \mathrm{~km}$ to the southeast of Okinawa Island. Cluster OK-RB is distributed around $26.0^{\circ} \mathrm{N}, 128.5^{\circ} \mathrm{E}$, which is to the northeast of OK-RA. The clusters of LFEs are complementary with the SSE faults in the Okinawa area. The short-term SSE faults are distributed between clusters OK-RA and OK-RB, and the LFEs are not active in the area of the SSE faults. Cluster OK-RC is approximately $70 \mathrm{~km}$ southeast of Okinoerabu Island (Fig. 12b). The activity of the LFEs is low to the southwest 

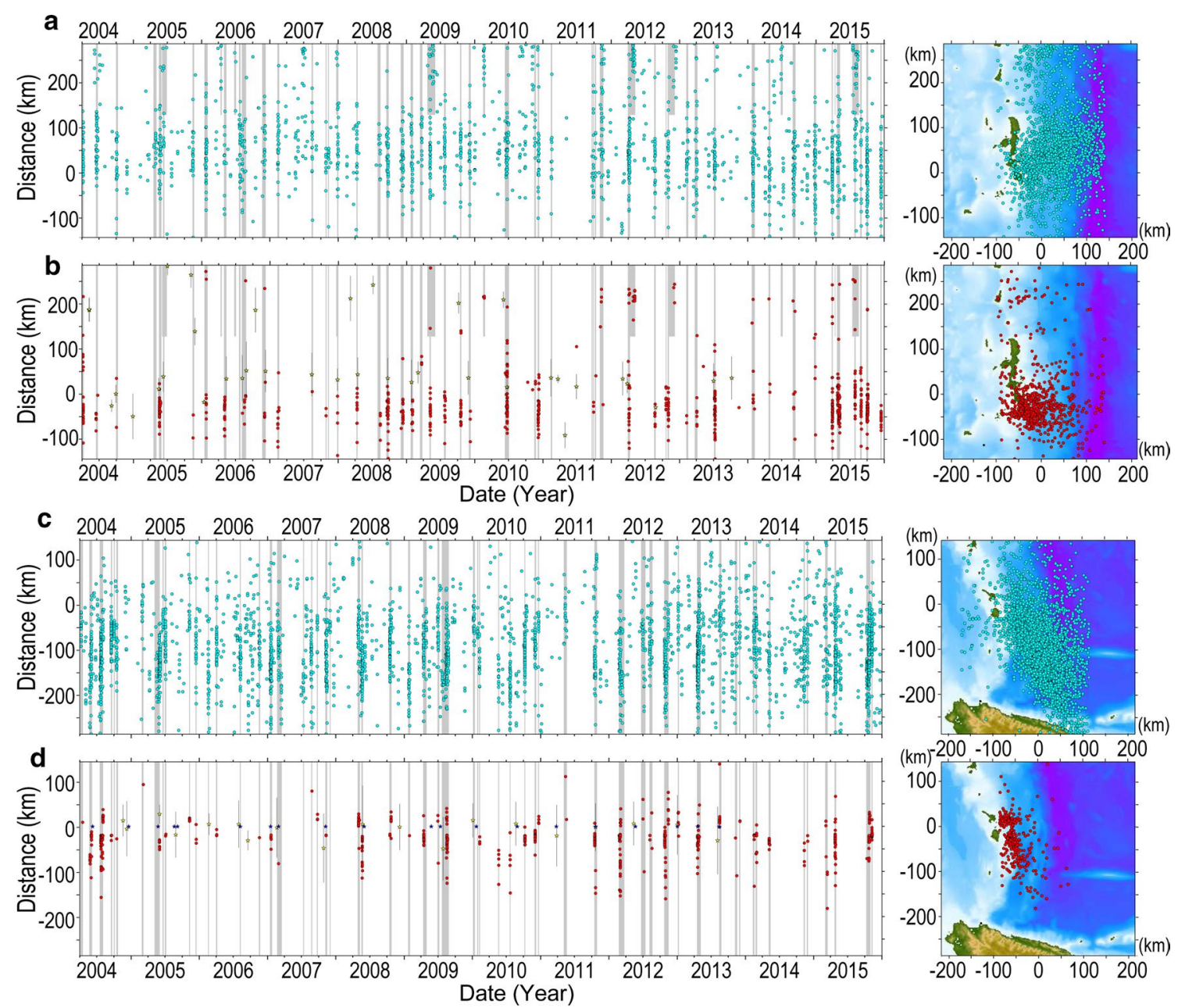

Fig. 8 Time-space plots of very low frequency earthquakes (VLFEs) and low-frequency earthquakes (LFEs). a Time-space plot of VLFEs in the Okinawa area from April 2004 to December 2015. Blue dots denote the VLFEs. The catalog of the VLFEs is based on Nakamura and Sunagawa (2015) with later events added. Vertical lines with yellow stars show the SSE faults (Nishimura 2014). Gray hatched areas show the periods for which the analyses of the LFEs were calculated. b Same as a but for LFEs. Red colors show the LFEs. c Same as a but for the Yaeyama area. d Same as b but for the Yaeyama area. Blue stars show the occurrence dates of SSEs in the Yaeyama area cataloged by Nakamura and Sunagawa (2015)

of cluster OK-RA. It is noted that this low activity might be a consequence of the lack of detection capability because the area is far from the seismic network.

The LFEs of the Yaeyama area occur in the region where the depth of the subducted plate is $12-25 \mathrm{~km}$ (Fig. 12a). The hypocenters of 217 LFEs are determined in the Yaeyama area. The magnitude range of the LFEs is -0.6 to 1.9 , and the horizontal hypocenter error is approximately $15 \mathrm{~km}$ (Fig. $7 \mathrm{a}, \mathrm{c}$ ). In the Yaeyama area, the relocated epicenters are distributed approximately $50 \mathrm{~km}$ to the south of the previous ones (Fig. 13a).

The distribution of LFEs can be divided into three major clusters (YA-RA, YA-RB, and YA-RC). Cluster YA-RA was distinguished from cluster YA-RB because the epicenters of YA-RA originated from cluster YA-A (Fig. 13a). The three clusters are $30-120 \mathrm{~km}$ from the trench axis.
Cluster YA-RA is located around $123.1^{\circ}-123.3^{\circ} \mathrm{E}$. Cluster YA-RB, which is the most active cluster, is located at $123.4^{\circ}-124.0^{\circ} \mathrm{E}$. Cluster YA-RC is located at $124.2^{\circ}-$ $124.6^{\circ} \mathrm{E}$. These clusters are approximately $50 \mathrm{~km}$ from the faults where SSEs occur repeatedly beneath Iriomote Island. The activity of the LFEs is low to the west of cluster YA-RA and to the east of cluster YA-RC. Again, this low activity might be a function of the lack of detection capability because of the distance from the seismic network.

\section{Discussion}

\section{Maximum amplitudes of LFE-VLFEs and ordinary earthquakes}

The LFEs analyzed in this study accompanied the VLFEs. Thus, the low- and high-frequency components of seismically slow earthquakes correspond to VLFEs and 

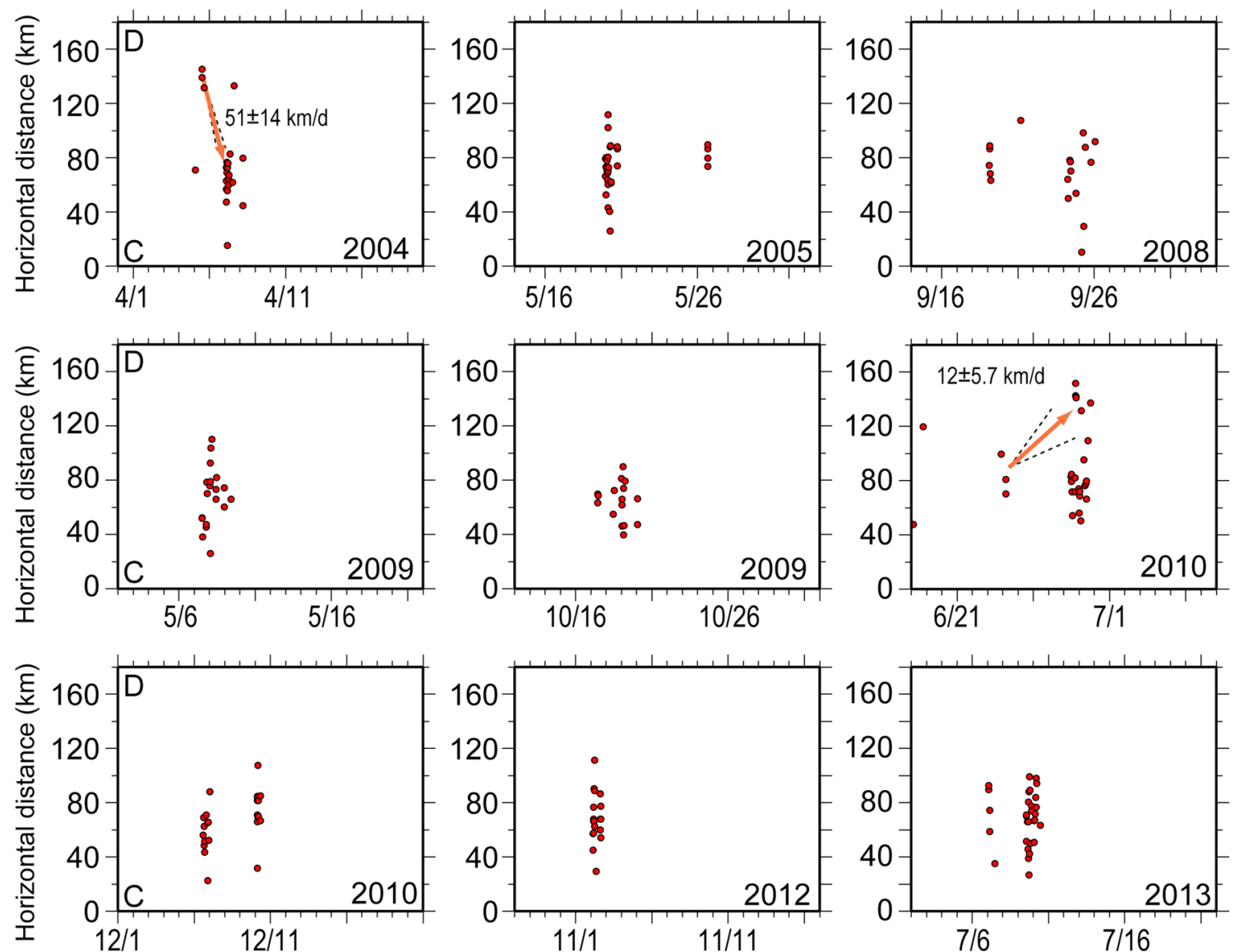

Fig. 9 Time-space plot of low-frequency earthquake (LFE) swarm in the Okinawa area. The swarm is plotted when the number of events was $>18$. The plotted area and annotations of C and D are denoted in Fig. 6b. Red circles show the LFEs. Arrows and dotted lines show the direction of LFE migration and its error range, respectively

LFEs, respectively. The amplitudes of the LFEs are 1\% than those of ordinary earthquakes. The distributions of ordinary earthquakes and LFEs are not continuous, but instead they show gaps. This suggests that the group of LFEs is different to the group of ordinary earthquakes and that the scaled energy (i.e., the ratio of seismic energy to seismic moment) of the LFEs is much smaller than that of ordinary earthquakes. In the Kii Peninsula of southwest Japan, the envelope of tremors with high frequency $(2-8 \mathrm{~Hz})$ is proportional to that of low frequency $(0.005-$ $0.500 \mathrm{~Hz})$ and the moment rate function, and the scaled energy is of the order of four to five times smaller than ordinary earthquakes (Ide et al. 2008). The envelope of the LFEs is also similar to the VLFEs at IGK (Fig. 2c-e). Calculating the seismic energy using the equation for the RMS waveform of LFEs (Ide et al. 2008), and calculating the seismic moment using the empirical equation for the maximum amplitude and moment magnitude (Ando et al. 2012), suggested that the scaled energy was of the order of $10^{-11}$ for the three events shown in Fig. 2c-e.
This value is approximately the same as for the case of deep tremors in the Kii Peninsula.

Sometimes, LFEs could not be observed when the VLFE swarm occurred. Therefore, two scenarios are proposed to account for this. The first is that the LFEs are sometimes obscured by background noise. In comparison with ordinary earthquakes, the amplitudes of LFEs are close to the noise level. When the noise is increased, the LFEs are obscured and their detection becomes more difficult. The distribution of the LFE-VLFE ceases near the average noise levels of the high $(3.8-4.1 \mathrm{~nm} / \mathrm{s})$ - and low $(2.1-2.2 \mathrm{~nm} / \mathrm{s})$-frequency components (Fig. 11). This suggests that the LFEs would be easily obscured by noise.

The second scenario considers the heterogeneity of the LFE-VLFE faulting. The LFEs correspond to the high-frequency components of the ruptures of the VLFEs. If the frictional conditions were heterogeneous and the VLFEs occurred in an area where highfrequency rupture was limited, the occurrence of the accompanying LFEs would be weak. In the area of the 

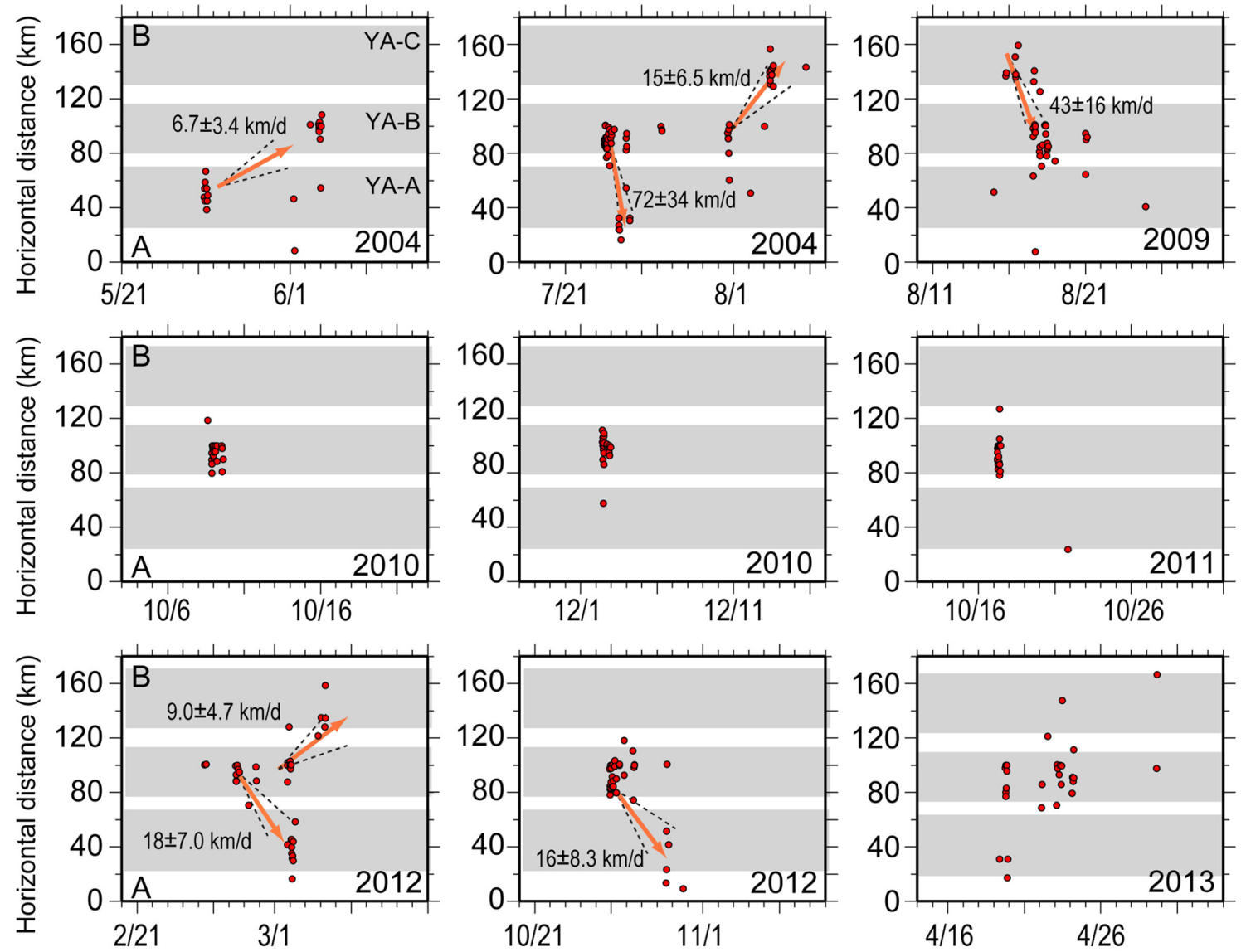

Fig. 10 Time-space plot of low-frequency earthquake (LFE) swarm in the Yaeyama area. The swarm is plotted when the number of events was $>18$. The plotted area and annotations of $A$ and $B$ are denoted in Fig. $6 a$. Red circles show the LFEs. Arrows and dotted lines show the direction of LFE migration and its error range, respectively. Gray hatched areas show clusters YA-A, YA-B, and YA-C

Okinawa Islands, LFE-VLFEs occur around the edge of the SSE faults. This suggests that the frictional conditions within the areas of the SSEs and LFE-VLFEs are not homogeneous within the Ryukyu Trench and that this would generate a difference in the degree of excitation of the LFEs.

\section{Distributions of SSEs, LFE-VLFEs, and ordinary earthquakes}

The distributions of SSEs, LFE-VLFEs, and ordinary earthquakes are complementary to each other at slab depths of $12-25 \mathrm{~km}$ in the Okinawa and Yaeyama areas (Fig. 12). The degree of interplate coupling changes the dip direction in the Yaeyama area (Arai et al. 2016). In this model, a tsunami earthquake zone is distributed near the trench axis to a plate depth of $15 \mathrm{~km}$, an LFE zone is distributed at depths of $15-25 \mathrm{~km}$, and the SSE zone is at depths $>25 \mathrm{~km}$. The results of this study suggest that the state of interplate coupling not only changes the dip direction, but it also changes the strike direction (Fig. 14).
The depths of LFEs range from 12 to $25 \mathrm{~km}$ in the Okinawa and Yaeyama areas when they occur on the subducted plate interface (Fig. 12). This depth is similar to the depth range of LFEs in Hyuga-nada (southwest Japan), where VLFEs occur at depths of 0-20 km (Asano et al. 2015). However, unlike the case in the Okinawa and Yaeyama regions, tremors also occur near the trench axis in the Hyuga-nada region. As the Ryukyu Trench is approximately $100 \mathrm{~km}$ or more from the seismic stations, the detection of LFE signals is difficult. The limitation of poor detection accounts for the lack of events observed near the trench. However, if the magnitudes of the LFEs that occurred near the trench axis were large, they would be detected by the seismic network. The rare detection of LFE activity near the trench axis suggests the possibility that large LFEs do not occur in that area.

The small-scale distribution of various types of slow earthquake in the Ryukyu Trench could be generated by the rugged topography of the plate interface. For example, there are undulations on the subducted plate in the 

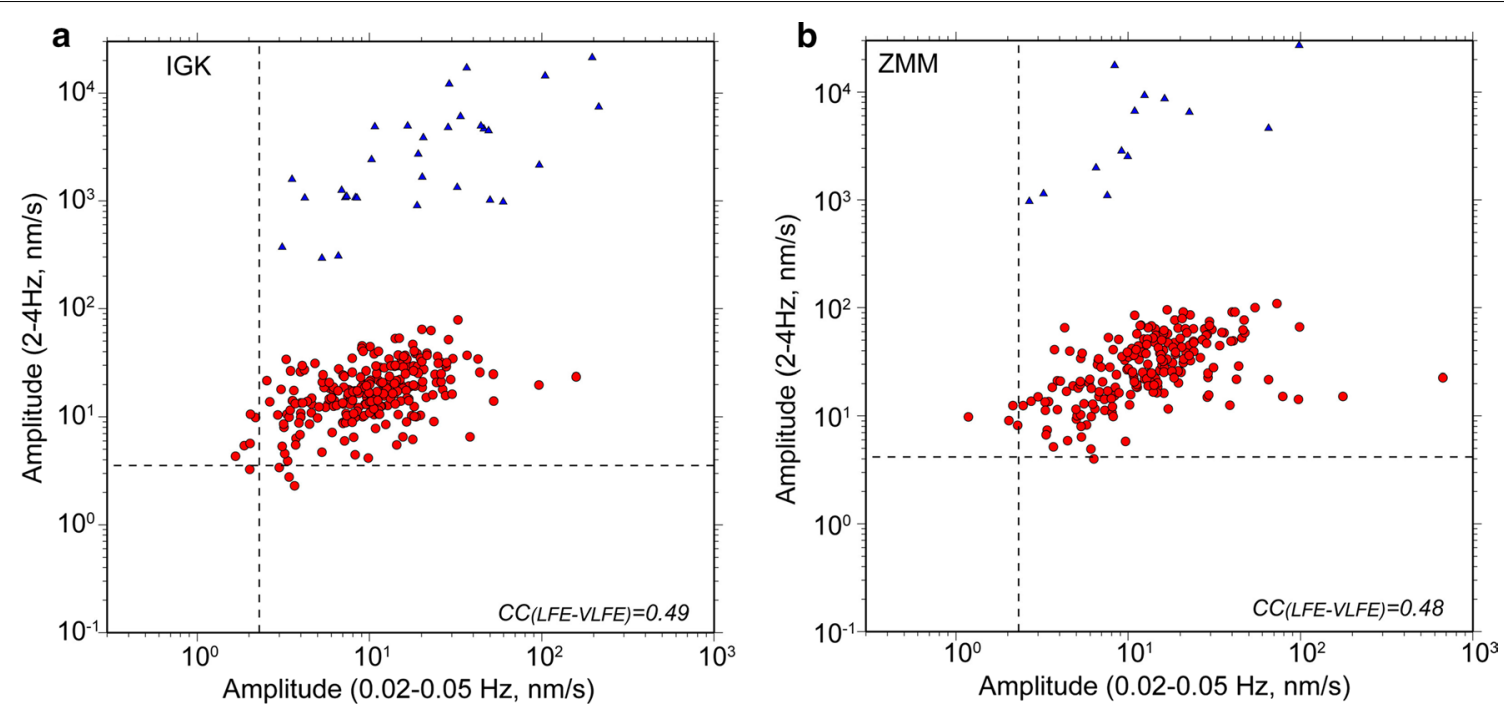

Fig. 11 Maximum amplitude of low-frequency earthquakes (LFEs) and very low frequency earthquakes (VLFEs). a Red circles show the maximum amplitude of LFEs as a function of association with VLFEs at IGK. Blue triangles denote the maximum amplitude of ordinary earthquakes within the frequency range $2.00-4.00 \mathrm{~Hz}$ as a function of the frequency range of $0.02-0.05 \mathrm{~Hz}$. The hypocenters of the ordinary earthquakes are distributed within $23.3^{\circ}-23.7^{\circ} \mathrm{N}, 123.3^{\circ}-124.7^{\circ} \mathrm{E}$ at depths of $<40 \mathrm{~km}$ (Fig. 1a). Horizontal and vertical lines denote the averaged noise level in the frequency ranges of $2.00-4.00$ and $0.02-0.05 \mathrm{~Hz}$ at IGK, respectively. b Same as a but at ZMM
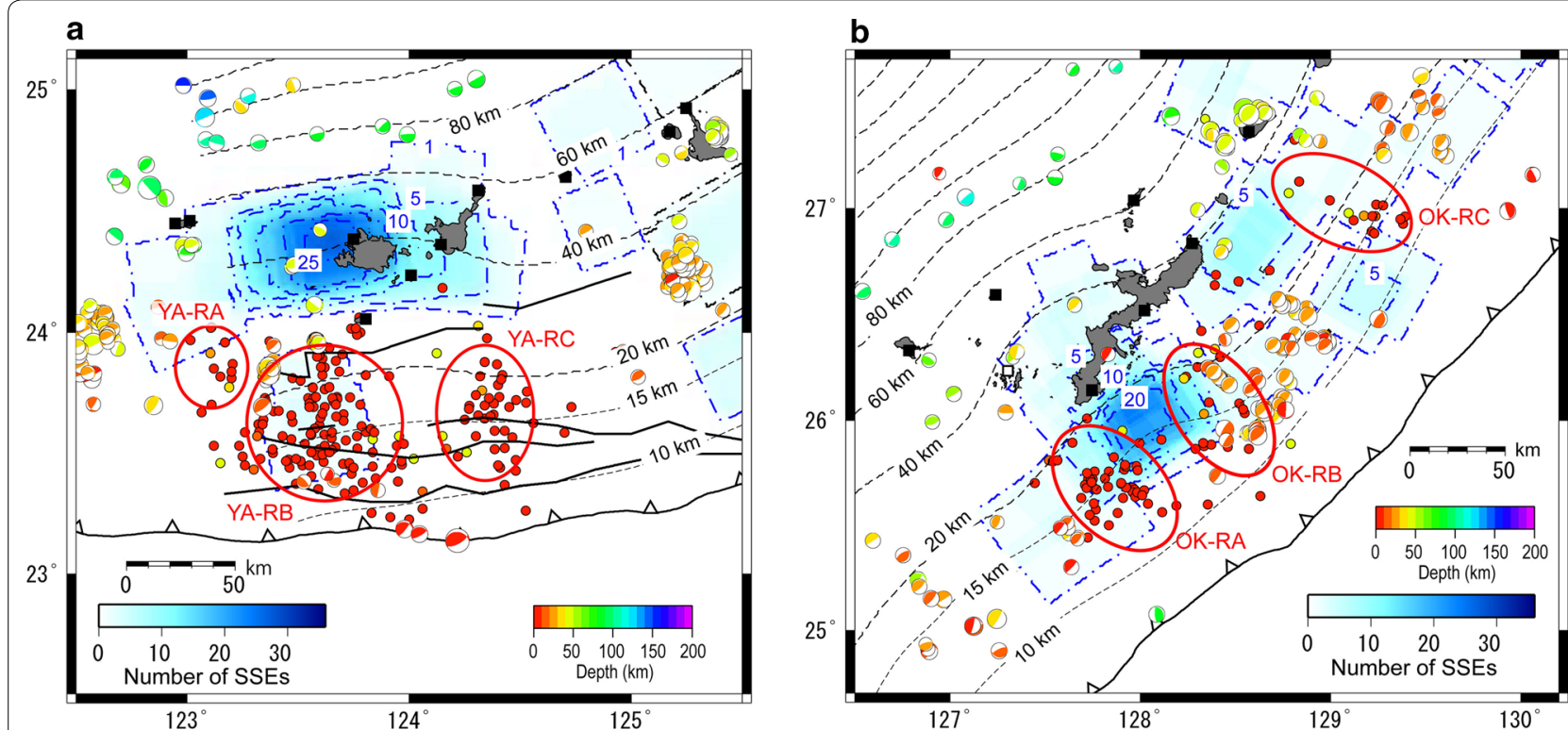

Fig. 12 Distributions of low-frequency earthquakes (LFEs) in the Yaeyama and Okinawa areas. a Distribution of hypocenters (solid circles) in the Yaeyama area. The centroid moment tensor (CMT) solutions are thrust-fault events (Mw > 3.5), which were selected from the F-net catalog of the National Research Institute for Earth Science and Disaster Resilience. The color of the CMT solutions indicates the depth of the event. Thick and thin dashed lines show the contours of the subducted Philippine Sea Plate, produced using SLAB1.0 (Hayes et al. 2012). Color map with blue long and short dashed lines shows the numbers of SSE faults (Nishimura 2014). b Same as a but for the Okinawa area

Okinawa area in the region of the Daito and Oki-Daito ridges, which are former island arcs (Hickey-Vargas et al. 2013; Shiki et al. 1979). Furthermore, the subducted Philippine Sea Plate has undulations beneath the Yaeyama area because of the collision with Taiwan. The subducted plate is deformed in the E-W direction (Wang et al. 2004) and the area of deformation extends to $123.3^{\circ} \mathrm{E}$. Moreover, the Gagua Ridge is subducting at $123.0^{\circ} \mathrm{E}$. The 

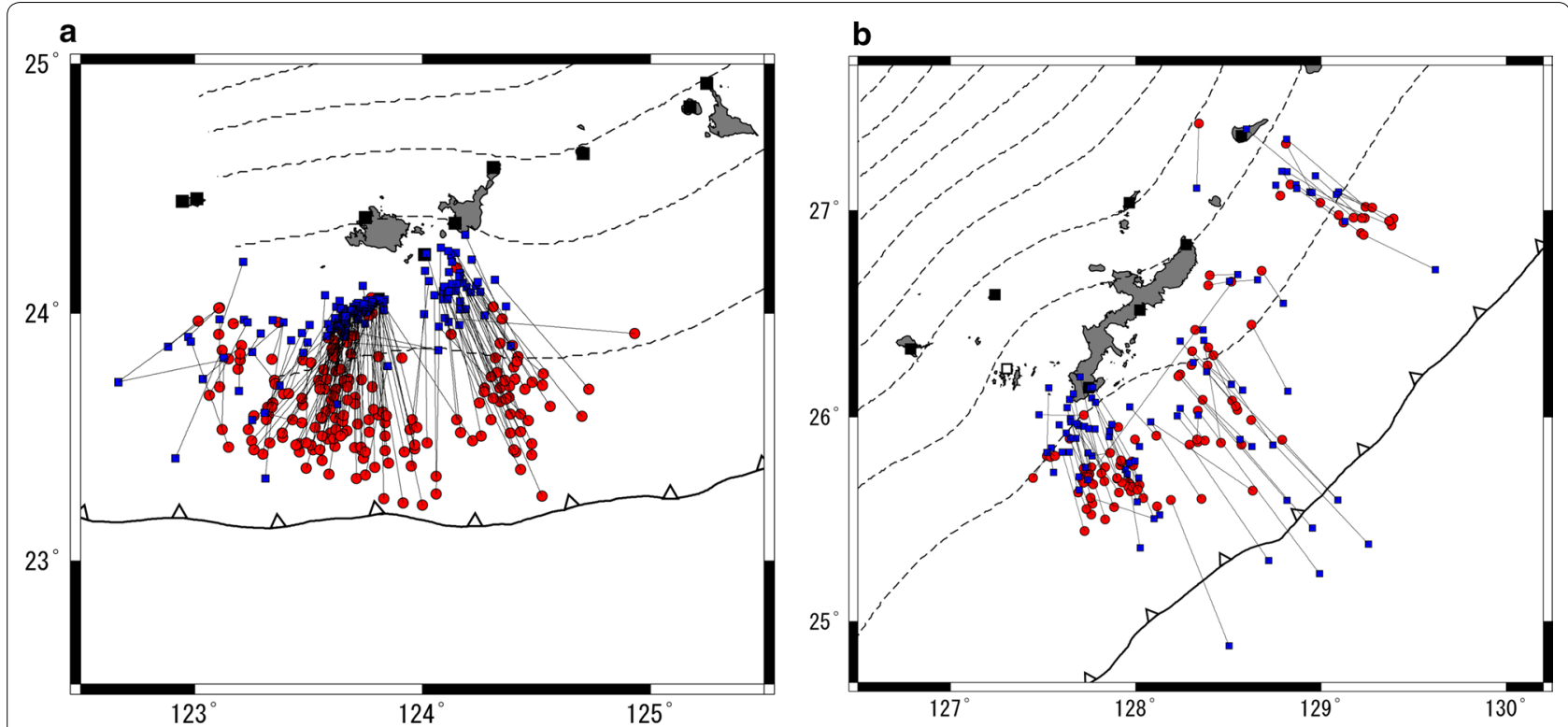

Fig. 13 Differences in epicenters between cross-correlation only and cross-correlation plus S-P time delays. a Difference in epicenters in the Yaeyama area. Blue squares show the epicenters determined using the cross-correlation of the envelope. Red circles show the epicenters determined using the cross-correlation of the envelope and S-P time delays. $\mathbf{b}$ Same as $\mathbf{a}$ but for the Okinawa area

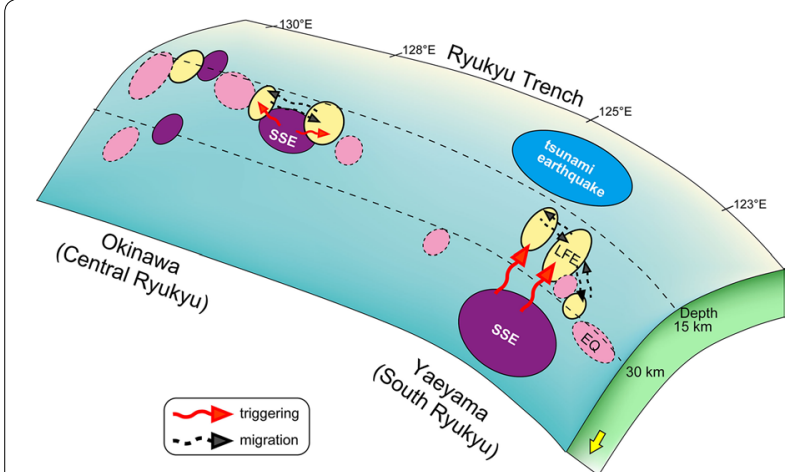

Fig. 14 Schematic diagram illustrating the distribution of slow earthquakes in the Ryukyu Subduction Zone. Pink circular areas with dotted lines show the areas of ordinary thrust-type earthquakes. Yellow circular areas show the areas of low-frequency earthquakes (LFEs). Purple circular areas show the slow slip event (SSE) faults (Nishimura 2014). Blue oval denotes the source area of the 1771 Yaeyama tsunami earthquake (Nakamura 2009). Red arrows show the triggering of LFEs by SSEs. Black arrows with dotted lines show the migration of LFES

subduction of such a rugged plate interface generates a combination of steady and episodic creep, which triggers small-to-moderate earthquakes (Wang and Bilek 2014). The patch-like distribution of various states of slip could be caused by the heterogeneous topography of the subducted plate.

The spread of LFE activity is relatively common in the Yaeyama area, and it might occur in the Okinawa area, although only two events have been detected. The averaged migration velocity ranges from 6.7 to $72 \mathrm{~km} /$ day. This is similar to the migration velocity of shallow tremors (30.0-60.0 km/day) and VLFEs $(10.0 \mathrm{~km} /$ day $)$ in the Hyuga-nada region (Asano et al. 2015; Yamashita et al. 2015). The migration of shallow VLFEs in the Hyuganada area is likely caused by the propagation of shallow SSEs (Asano et al. 2015). Applying the Hyuga-nada model to the Okinawa and Yaeyama areas suggests that the LFEs and VLFEs in these regions coincide with the shallow SSEs.

The LFEs could be detected only near Okinawa and Iriomote islands. The detection ability is limited to near the islands because the distribution of the seismic stations is restricted and the magnitudes of the LFEs are small $(-0.6$ to 1.9$)$. In the southwestern part of OK-RA in the Okinawa area, and the western part of YA-RA and eastern part of YA-RC in the Yaeyama area, detection ability is decreased. If LFEs were to occur in these areas, they would not be detected by the seismic network.

\section{Cause of contrasting distributions of SSEs and LFE-VLFEs in the Okinawa and Yaeyama areas}

As mentioned above, the LFE swarm could be related to shallow SSE faulting. Actually, the LFE-VLFE swarms do coincide with the SSEs (Fig. 8); however, the relative locations of the SSEs and clusters of LFEs are different in the Okinawa and Yaeyama areas. In the case of the Okinawa area, the VLFEs and LFEs occur in association with the 
SSEs, and the LFEs occur on the edges of the SSE faults (Fig. 12b). This is similar to the relation between SSEs and microearthquakes on the Boso Peninsula in central Japan. The SSEs on this peninsula accompany ordinary earthquakes that occur on the SSE fault edges in the strike and downdip directions (Hirose et al. 2014; Sagiya 2004). Applying the case of the Boso Peninsula SSEs to the Okinawa area suggests that the LFEs in the Okinawa area could be generated by stress accumulation on the edge of the rupture area.

In the case of the Yaeyama area, the VLFEs and LFEs occur in association with the SSEs, but the distribution of the LFEs is approximately $50 \mathrm{~km}$ away from the SSE faults (Fig. 12a). Similar triggering is observed in the Bungo Channel of southwestern Japan and in New Zealand. In the Bungo Channel, the outer edge of which was the source of the 1946 Nankai earthquake, shallow VLFEs (depth of $5 \mathrm{~km}$ ) occur near the trench axis in association with the occurrence of deep SSEs (Mw 6.8, depth: $40 \mathrm{~km}$ ), even though these two types of slow earthquake are $100 \mathrm{~km}$ apart (Hirose et al. 2010). In the case of the Bungo Channel, the slip of the deep SSEs propagates to the shallow part of the plate interface, where it changes the strain in the VLFE source area and activates the shallow VLFEs. Short-term shallow SSEs (depth $<15 \mathrm{~km}$ ), triggered by the Coulomb failure stress change $(1-15 \mathrm{kPa})$ of the deep long-term SSEs (depth 25-60 km), were observed in 2010-2011 in New Zealand (Wallace et al. 2012). In the initial stage of the shallow SSEs in New Zealand, earthquake activity migrated. In the case of the Yaeyama area, the shear stress on the plate interface is increased by approximately $1 \mathrm{kPa}$ by the SSEs beneath Iriomote Island (Nakamura and Sunagawa 2015). The small SSEs accompanying the LFE-VLFE swarm near the southern Ryukyu Trench have not been detected because the Global Navigation Satellite System network on the islands is far from the trench axis. However, applying the case of New Zealand to the Yaeyama area suggests that undetected small shallow SSEs near the trench axis could have been triggered by the stress change of deep SSEs beneath Iriomote Island, and they would have induced LFEs and VLFEs near the small and shallow SSEs.

\section{Possibility of occurrence of LFEs on splay faults}

In the Yaeyama area, a splay fault is developed along the Ryukyu Trench. Splay faults are reverse-type faults, and in this scenario, they are $20-50 \mathrm{~km}$ from the trench axis (Arai et al. 2016; Hsu et al. 2013). One splay fault, which is $40 \mathrm{~km}$ from the trench axis, has right-lateral strike-slip movement (Hsu et al. 2013) (Fig. 12a). The movement of this fault functions as a stress partition due to oblique subduction of the Philippine Sea Plate (Lallemand et al. 1999). However, analysis of the seafloor topography suggests that the activity of the strike-slip fault is low (Izumi et al. 2016). As some LFE-VLFEs are located near the strike-slip splay faults, LFEs might occur not only on the plate interface but also on the splay faults (Fig. 12a). In the shallow part of the Nankai Trough, VLFEs do occur not only on the plate interface (Sugioka et al. 2012) but also on the accretionary prism (Ito and Obara 2006).

Observations by ocean-bottom seismometers in the southern Ryukyu Trench have revealed that the LFEs occur on the plate interface (Arai et al. 2016). Although the observational periods are only 3 months, the distribution of the epicenters is consistent with the 12-year longterm distribution. This suggests that most LFEs would occur on the plate interface; however, some might occur on the splay faults. Long-term observations using oceanbottom seismometers placed above the hypocenter area of LFEs would reveal whether all LFEs occur on the plate interface.

\section{Conclusions}

The distribution of LFEs accompanying VLFEs along the central and southern Ryukyu Trench revealed the heterogeneous structure of the seismogenic zone of the trench. The distributions along the trench of SSEs, LFE-VLFEs, and thrust-type ordinary earthquakes were found to be complementary. Such heterogeneous distribution could be caused by the small-scale rugged topography of the subducting plate. In the central and southern Ryukyu Trench, the topography of the subducting plate is very rugged, i.e., a former island arc is being subducted and plate undulation is developing. Although the state of frictional condition changes toward the dip direction, such structural heterogeneity could locally alter the degree of interplate coupling and the state of slip along the trench axis.

The SSEs in the southern and central Ryukyu Trench induced the LFE-VLFEs; however, the locations of the SSE faults varied in both areas. In the central Ryukyu Trench, the SSEs were distributed at depths similar to the LFEs. Conversely, the SSEs in the southern Ryukyu Trench were distributed $50 \mathrm{~km}$ from the LFE-VLFE clusters. In the case of the Yaeyama area, either the rupture of repeating SSEs that propagated to near the trench axis or the small stress accumulation by the SSEs triggered the LFEs near the trench.

This study established that SSEs affect LFE-VLFE activity. The source area of tsunami earthquakes is distributed in the shallow part of the subduction zone near the Ryukyu Trench. Surrounding SSE and LFE-VLFE activity could transfer stress to the tsunami earthquake area, where it might accumulate. The geodetically and seismically slow earthquakes contribute to the process of stress accumulation in the Ryukyu Trench. The 
investigation of this process of stress transfer through slow earthquakes could reveal the mechanism of tsunami earthquakes.

\section{Abbreviations}

CMT: centroid moment tensor; JMA: Japan Meteorological Agency; LFE: lowfrequency earthquake; RMS: root-mean-square; SSE: slow slip event; VLFE: very low frequency earthquake.

\section{Acknowledgements}

I thank the Japan Meteorological Agency for providing the short-period seismic data and hypocenter catalog. I would also like to thank the National Research Institute for Earth Science and Disaster Resilience for providing the F-net broadband seismic data. I thank Kentaro Yoshida for cooperating in the collection of the JMA waveform data. These data can be obtained from the author upon request (mnaka@sci.u-ryukyu.ac.jp). I thank two anonymous reviewers whose comments helped to improve and refine the manuscript significantly. This work was supported partially by JSPS KAKENHI Grant Number JP16H06473.

\section{Competing interests}

The author declares that he has no competing interests.

\section{Publisher's Note}

Springer Nature remains neutral with regard to jurisdictional claims in published maps and institutional affiliations.

Received: 20 December 2016 Accepted: 28 March 2017

Published online: 05 April 2017

\section{References}

Ando M, Nakamura M, Matsumoto T, Furukawa M, Tadokoro K, Furumoto M (2009) Is the Ryukyu subduction zone in Japan coupled or decoupled? The necessity of seafloor crustal deformation observation. Earth Planets Space 61:1031-1039. doi:10.1186/BF03352954

Ando M, Tu Y, Kumagai H, Yamanaka T, Lin CH (2012) Very low frequency earthquakes along the Ryukyu subduction zone. Geophys Res Lett 39:L04303. doi:10.1029/2011GL0505

Arai R, Takahashi T, Kodaira S, Kaiho Y, Nakanishi A, Fujie G, Nakamura Y, Yamamoto Y, Ishihara Y, Miura S, Kaneda Y (2016) Structure of the tsunamigenic plate boundary and low-frequency earthquakes in the southern Ryukyu Trench. Nat Commun 7:12255. doi:10.1038/ncomms12255

Asano Y, Obara K, Matsuzawa T, Hirose H, Ito Y (2015) Possible shallow slow slip events in Hyuga-nada, Nankai subduction zone, inferred from migration of very low frequency earthquakes. Geophys Res Lett 42:331-338. doi:10. 1002/2014GL062165

Bird P (2003) An updated digital model of plate boundaries. Geochem Geophys Geosyst 4:1027. doi:10.1029/2001GC000252

Chao K, Peng Z, Huizar HG, Aiken C, Enescu B, Kao H, Velasco AA, Obara K, Matsuzawa T (2013) A global search for triggered tremor following the 2011 Mw 9.0 Tohoku Earthquake. Bull Seismol Soc Am 103:1551-1571. doi:10.1785/0120120171

Hayes GP, Wald DJ, Johnson RL (2012) Slab1.0: a three-dimensional model of global subduction zone geometries. J Geophys Res 117:B01302. doi:10.1 029/2011JB008524

Heki K, Kataoka T (2008) On the biannually repeating slow-slip events at the Ryukyu Trench, southwestern Japan. J Geophys Res 113:B11402. doi:10.1 029/2008JB005739

Hickey-Vargas R, Ishizuka O, Bizimis M (2013) Age and geochemistry of volcanic clasts from DSDP Site 445, Daito Ridge and relationship to Minami-Daito Basin and early Izu-Bonin arc magmatism. J Asian Earth Sci 70-71:193-208. doi:10.1016/j.jseaes.2013.03.013

Hirose H, Asano Y, Obara K, Kimura T, Matsuzawa T, Tanaka S, Maeda T (2010) Slow earthquakes linked along dip in the Nankai subduction zone. Science 330:1502. doi:10.1126/science.1197102
Hirose H, Matsuzawa T, Kimura T, Kimura H (2014) The Boso slow slip events in 2007 and 2011 as a driving process for the accompanying earthquake swarm. Geophys Res Lett 41:2014GL059791. doi:10.1002/2014GL059791

Hsu SK, Yeh YC, Sibuet JC, Doo WB, Tsai CH (2013) A mega-splay fault system and tsunami hazard in the southern Ryukyu subduction zone. Earth Planet Sci Lett 362:99-107. doi:10.1016/j.epsl.2012.11.053

Ide S, Shelly DR, Beroza GC (2007) The mechanism of deep low frequency earthquakes: further evidence that deep non-volcanic tremor is generated by shear slip on the plate interface. Geophys Res Lett 34:L03308. doi :10.1029/2006GL028890

Ide S, Imanishi K, Yoshida Y, Beroza GC, Shelly DR (2008) Bridging the gap between seismically and geodetically detected slow earthquakes. Geophys Res Lett 35:L10305. doi:10.1029/2008GL034014

Ito Y, Obara K (2006) Very low frequency earthquakes within accretionary prisms are very low stress-drop earthquakes. Geophys Res Lett 33:L09302. doi:10.1029/2006GL025883

Ito Y, Hino R, Kido M, Fujimoto H, Osada Y, Inazu D, Ohta Y, linuma T, Ohzono M, Miura S, Mishina M, Suzuki K, Tsuji T, Ashi J (2013) Episodic slow slip events in the Japan subduction zone before the 2011 Tohoku-Oki earthquake. Tectonophysics 600:14-26. doi:10.1016/j. tecto.2012.08.022

Izumi N, Nishizawa A, Horiuchi D, Kido Y, Goto H, Nakata T (2016) 3D bathymetric image of Nansei-Shoto Trench and its vicinity. Rep Hydrol Ocean Res 53:133-149 (in Japanese)

Kato A, Nakagawa S (2014) Multiple slow-slip events during a foreshock sequence of the 2014 lquique, Chile Mw 8.1 earthquake. Geophys Res Lett 41:5420-5427. doi:10.1002/2014GL061138

Kato A, Fukuda J, Kumazawa T, Nakagawa S (2016) Accelerated nucleation of the 2014 lquique, Chile Mw 8.2 earthquake. Sci Rep 6:24792. doi:10.1038/ srep24792

Lallemand LiuCS, Dominguez S, Schnurle P, Malavieille J, The ACT Scientific Crew (1999) Trench-parallel stretching and folding of forearc basins and lateral migration of the accretionary wedge in the southern Ryukyus: a cause of strain partition caused by oblique convergence. Tectonics $18: 231-247$

Nakamura M (2009) Fault model of the 1771 Yaeyama earthquake along the Ryukyu Trench estimated from the devastating tsunami. Geophys Res Lett 36:L19307. doi:10.1029/2009GL039730

Nakamura M, Sunagawa N (2015) Activation of very low frequency earthquakes by slow slip events in the Ryukyu Trench. Geophys Res Lett 42:1076-1082. doi:10.1002/2014GL062929

Nishimura T (2014) Short-term slow slip events along the Ryukyu trench, southwestern Japan, observed by continuous GNSS. Prog Earth Planet Sci 1:22. doi:10.1186/s40645-014-0022-5

Obara K (2002) Nonvolcanic deep tremor associated with subduction in southwest Japan. Science 296(5573):1679-1681

Obara K, Kato A (2016) Connecting slow earthquakes to huge earthquakes. Science 353(6296):253-257. doi:10.1126/science.aaf1512

Peterson ET, Seno T (1984) Factors affecting seismic moment release rates in subduction zones. J Geophys Res 89:10233-10248

Sagiya T (2004) Interplate coupling in the Kanto district, central Japan, and the Boso Peninsula silent earthquake in May 1996. Pure Appl Geophys 161:2327-2342

Seno T, Stein S, Gripp AE (1993) A model for the motion of the Philippine Sea plate consistent with NUVEL-1 and geological data. J Geophys Res 98:17941-17948. doi:10.1029/93JB00782

Shelly DR, Beroza GC, Ide S, Nakamula S (2006) Low-frequency earthquakes in Shikoku, Japan, and their relationship to episodic tremor and slip. Nature 442:188-191. doi:10.1038/nature04931

Shiki T, Misawa Y, Konda I (1979) The Daito Ridge group and the Kyushu-Palau Ridge: with special reference to the tectonics of the Philippine Sea. J Physics Earth 27(suppl):S113-S124

Sugioka H, Okamoto T, Nakamura T, Ishihara Y, Ito A, Obana K, Kinoshita M, Nakahigashi K, Shinohara M, Fukao Y (2012) Tsunamigenic potential of the shallow subduction plate boundary inferred from slow seismic slip. Nat Geosci 5:414-418. doi:10.1038/ngeo1466

Ueno H, Hatakeyama S, Aketagawa T, Funasaki J, Hamada N (2002) Improvement of hypocenter determination procedures in the Japan Meteorological Agency. Q J Seismol 65:123-134 (in Japanese)

Wallace LM, Beavan J, Bannister S, Williams C (2012) Simultaneous long-term and short-term slow slip events at the Hikurangi subduction margin, New 
Zealand: Implications for processes that control slow slip event occurrence, duration, and migration. J Geophys Res 117:B11402. doi:10.1029/2 012JB009489

Wang KS, Bilek L (2014) Invited review paper: fault creep caused by subduction of rough seafloor relief. Tectonophysics 610:1-24. doi:10.1016/j. tecto.2013.11.024

Wang TK, Lin SF, Liu CS, Wang CS (2004) Crustal structure of the southernmost Ryukyu subduction zone: OBS, MCS and gravity modelling. Geophys J Int 157:147-163
Watanabe H (1971) Determination of earthquake magnitude at regional distance in and near Japan. Zisin II 24:189-200 (in Japanese with English abstract)

Yamashita Y, Yakiwara H, Asano Y, Shimizu H, Uchida K, Hirano S, Umakoshi K, Miyamachi H, Nakamoto M, Fukui M, Kamizono M, Kanehara H, Yamada T, Shinohara M, Obara K (2015) Migrating tremor off southern Kyushu as evidence for slow slip of a shallow subduction interface. Science 348(6235):676-679. doi:10.1126/science.aaa4242

\section{Submit your manuscript to a SpringerOpen ${ }^{\circ}$ journal and benefit from:}

- Convenient online submission

Rigorous peer review

- Immediate publication on acceptance

- Open access: articles freely available online

- High visibility within the field

- Retaining the copyright to your article 